\title{
No todo es neumonía adquirida en la comunidad. Neumonía eosinofílica aguda: reporte de caso
}

\author{
Not everything is community acquired pneumonia. \\ Acute eosinophilic pneumonia: Case report
}

\author{
Jorge Andrés Fernández Franco, MD ${ }^{1}$ Fair de Jesús Clavijo Tinoco, MD ${ }^{1}$ ERnesto Santiago \\ Henríquez, MD² Paulina OJeda León, MD ${ }^{3}$
}

\section{Resumen}

Los síndromes eosinofílicos pulmonares (SEP) comprenden un grupo heterogéneo de enfermedades que tienen en común la infiltración eosinofílica en el lavado broncoalveolar y la infiltración tisular en el análisis histopatológico. Se expone un caso correspondiente a una paciente de sexo femenino de 42 años quien consultó por un cuadro clínico agudo de tos, disnea y eosinofilia periférica, con estudios de imágenes torácicas compatibles con consolidación alveolar en ambos segmentos basales posteriores, la língula y el segmento lateral del lóbulo medio derecho. Se descartó parasitosis, infección por micobacterias, infección por hongos, virus respiratorios, patología oncológica y reumatológica. La biopsia de pulmón mostró un engrosamiento de los tabiques interalveolares con proliferación celular de linfocitos e histiocitos con hiperplasia alveolar, neumocitos atípicos y ocupación difusa de la luz con abundantes eosinófilos. El curso clínico y los hallazgos histopatológicos confirman el diagnóstico de neumonía eosinofílica aguda (NEA).

Palabras clave: eosinofilia, eosinofilia pulmonar, neumonía eosinofílica aguda, neumonía eosinofílica crónica.

\begin{abstract}
Eosinophilic lung disease (ELD) comprises a heterogeneous group of diseases that have in common eosinophilic infiltration in bronchoalveolar lavage and tissue infiltration in histopathological analysis. We expose a case of 42-year-old woman who was admitted to emergency room for cough, dyspnea and peripheral eosinophilia, with studies of thoracic images compatible with alveolar consolidation in posterior basal segments, the lingual and the lateral segment of the right middle lobe. Parasitism, mycobacterial infection, fungal infections, oncological and rheumatologic pathologies were ruled out. Lung biopsy showed thickening of the interalveolar septum with eosinophilic infiltration. Clinical course and histopathological findings make the diagnosis of acute eosinophilic pneumonia (AOP).
\end{abstract}

Keywords: Eosinophilia, pulmonary eosinophilia, acute eosinophilic pneumonia, chronic eosinophilic pneumonia.
${ }^{1}$ Residente de Medicina Interna, Universidad Libre. Barranquilla, Colombia.

${ }^{2}$ Medicina Interna, Neumología, Universidad Militar Nueva Granada. Bogotá D. C., Colombia.

${ }^{3}$ Anatomía Patológica, Colegio Mayor de Nuestra Señora Del Rosario. Bogotá D. C., Colombia.

Autor de correspondencia

Jorge Andrés Fernández Franco. Correo electrónico: jorgefernandezfranco11@ gmail.com

Recibido: 3/9/2018. Aceptado:

10/12/2018. 


\section{Introducción}

Los síndromes eosinofílicos pulmonares (SEP) comprenden un grupo heterogéneo de enfermedades que tienen en común la infiltración eosinofílica en el lavado broncoalveolar (LBA) y la infiltración tisular en el análisis histopatológico (1). De acuerdo con su presentación clínica y radiológica, los SEP se clasifican en: SEP de causas no definidas, SEP de causas determinadas y SEP de causas misceláneas (2) (Tabla 1).

La neumonía eosinofílica aguda (NEA) es una enfermedad febril de causa desconocida, no asociada con otras manifestaciones sistémicas; pertenece al grupo de los SEP de causas no definidas, que puede presentarse como un síndrome de dificultad respira- toria aguda (SDRA), con buena respuesta a los corticosteroides y con mínima tasa de recaídas (3). Los criterios diagnósticos de las NEA se describen en la Tabla 2. La eosinofilia pulmonar crónica se caracteriza por ser una enfermedad progresiva, recurrente, con fiebre, disnea, sudoración nocturna y pérdida de peso. Aunque la causa exacta de la neumonía eosinofílica es desconocida, uno de los factores desencadenantes descritos es el tabaco (4) y ocasionalmente las infecciones virales. El abordaje diagnóstico comprende historia clínica, estudios radiológicos, LBA y biopsia pulmonar. La piedra angular en el tratamiento son los corticosteroides, los cuales tienen muy buena respuesta. Se presenta el caso de una mujer de 42 años a quien se le diagnosticó NEA.

Tabla 1. Clasificación de los SEP

\begin{tabular}{|c|c|c|}
\hline De causa desconocida & De causa determinada & Miscelánea \\
\hline $\begin{array}{l}\text { Neumonía eosinofílica idiopática } \\
\text { (aguda y crónica) }\end{array}$ & De origen parasitario* & Neumonía organizada \\
\hline Síndrome hipereosinofílico & Otras causas infecciosas & Bronquitis eosinofílica y asma \\
\hline $\begin{array}{l}\text { Granulomatosis eosinofílica con } \\
\text { poliangitis (síndrome Churg-Strauss) }\end{array}$ & $\begin{array}{l}\text { Aspergilosis broncopulmonar alérgica y } \\
\text { otros síndromes asociados** }\end{array}$ & Neumonía intersticial idiopática \\
\hline Bronquiolitis obliterativa & $\begin{array}{l}\text { Asociados con medicamentos y } \\
\text { tóxicos }{ }^{* * *}\end{array}$ & Histiocitosis de células de Langerhans \\
\hline Hipereosinofilia idiopática & Asociados con radiación**** & Trasplante pulmonar \\
\hline
\end{tabular}

*Ascariasis, Larva migrans, infección por Strongyloides stercoralis, eosinofilia tropical. **Granulomatosis broncocéntrica y síndromes broncopulmonares asociados con hongos y quistes. ${ }^{* *}$ Ampicilina, cloroquina, daptomicina, etambutol, fluoxetina, minociclina, risperidona, triptófano, tacrolimus, amiodarona, ácido mefenámico, cocaína inhalada, síndrome de aceite tóxico.

${ }^{* * \star *}$ Asociada con la radioterapia en cáncer de mama. Tomado de: Cottin V. Clin Chest Med. 2016;37(3):535-56.

Tabla 2. Criterios diagnósticos de NEA

1. Inicio agudo de manifestaciones respiratorias febriles ( $\leq 1$ mes de evolución)

2. Opacidades difusas bilaterales en la radiografía de tórax

3. Hipoxemia $\left(\mathrm{PaO}_{2}<60 \mathrm{~mm} \mathrm{Hg}\right) \circ \mathrm{PaO}_{2} / \mathrm{FiO}_{2} \leq 300 \mathrm{~mm} \mathrm{Hg}$ o $\mathrm{SaO}_{2}<90 \%$ ambiente

4. Eosinofilia pulmonar, con $>25 \%$ de eosinófilos en el recuento diferencial de LBA (o neumonía eosinofílica en la biopsia pulmonar)

5. Ausencia de infección o de otras causas conocidas de enfermedad pulmonar eosinofílica (especialmente exposición a un medicamento susceptible de inducir eosinofilia pulmonar)

Tomado de: Cottin V. Clin Chest Med. 2016;37(3):535-56. 


\section{Descripción del caso}

Se trata de una paciente de 42 años, abogada de profesión, sin comorbilidades asociadas ni antecedentes personales de importancia con un cuadro clínico de 3 semanas de evolución caracterizado por tos aguda no hemoptoica, con expectoración hialina, sin predominio horario, asociado con fiebre cuantificada de 7 días de evolución con un patrón intermitente que mejora parcialmente con la ingesta de paracetamol, sin presencia de sudoración o escalofríos. Concomitante mencionó malestar general, astenia y adinamia, negó dolor torácico y disnea.

En el examen físico se encontraba en buen estado general, con presión arterial (PA): 120/70 mm Hg, frecuencia cardíaca (FC): 96 latidos por minuto (lpm), frecuencia respiratoria (FR): 20 respiraciones por minuto (rpm), temperatura: $37{ }^{\circ} \mathrm{C}$ y saturación de oxígeno $\left(\mathrm{SaO}_{2}\right)$ : $95 \%$; a nivel cardiopulmonar presentó ruidos respiratorios con estertores bilaterales bibasales, sin otros ruidos adventicios y ruidos cardíacos rítmicos sin soplos. No se evidenciaron adenopatías o lesiones en la piel. El hemograma resultó con leucocitosis a expensas de los neutrófilos y eosinófilos, la radiografía de tórax posteroanterior y lateral con disminución de la transparencia pulmonar dada por infiltrados de ocupación alveolar bilateral en los lóbulos inferiores con broncograma aéreo sin derrame pleural (Figura 1).

Ante estos hallazgos en el departamento de urgencias, impresionó un diagnóstico de neumonía adquirida en la comunidad (NAC) con índices de gravedad bajos como CRB 65: 0 (índice de gravedad que incluye $\mathrm{C}$ : compromiso de conciencia, $\mathrm{R}$ : frecuencia respiratoria y $\mathrm{B}$ : presión arterial) e índice de gravedad de neumonía (PSI) clase I, por lo cual se decidió dar un manejo ambulatorio con amoxicilina/ácido clavulánico durante 7 días. Luego de 2 semanas de haber culminado el tratamiento volvió a consultar al departamento de urgencias manifestando la persistencia de síntomas respiratorios altos, astenia y adinamia.
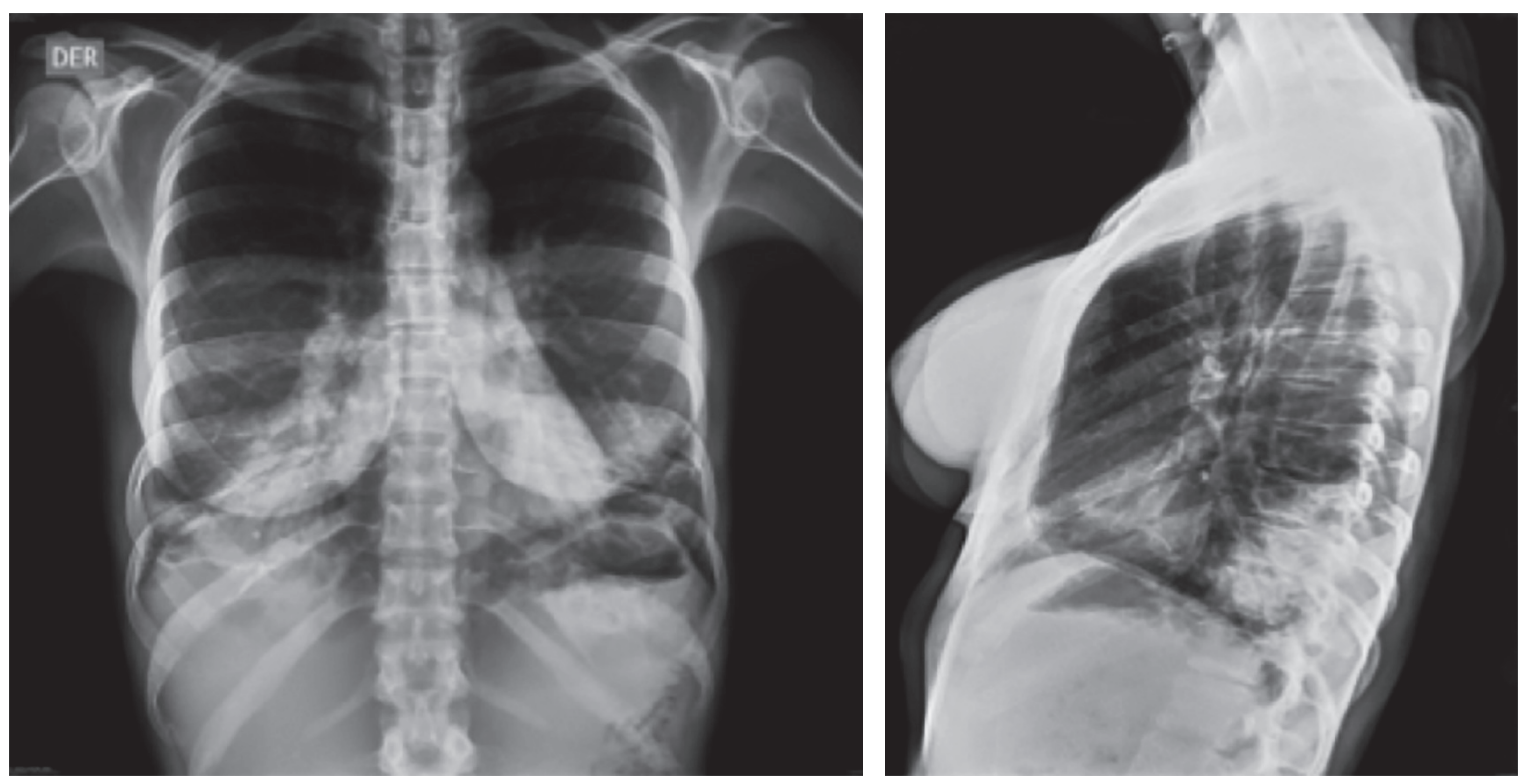

Figura 1. Radiografía de tórax en proyecciones anteroposterior y lateral de ingreso: disminución de la transparencia pulmonar dada por infiltrados de ocupación alveolar bilateral en ambos lóbulos inferiores con broncograma aéreo sin derrame pleural. 
En el examen físico la paciente se presentaba febril, taquipneica, taquicárdica, saturando $88 \%$ al oxígeno ambiente, persistencia de ruidos respiratorios con estertores bibasales y roncus espiratorios. El hemograma resultó con 15190 leucocitos $/ \mathrm{mm}^{3}$, neutrofilia de 80 $\%$ y eosinofilia de $11,1 \%$ (1690 eosinófilos $\left./ \mathrm{mm}^{3}\right)$. La proteína C-reactiva (PCR) resultó en $10 \mathrm{mg} / \mathrm{dL}$, con pruebas de función renal normales. La radiografía de tórax en esta ocasión mostró persistencia de consolidación de lóbulos inferiores con broncograma aéreo y acentuación de la trama intersticial bilateral, con derrame pleural derecho. La escanografía de tórax de alta resolución demostró extensas áreas con aumento de la atenuación pulmonar (franca consolidación) con broncograma aéreo, asociado con un patrón de vidrio deslustrado que comprometen ambos segmentos basales posteriores de los lóbulos inferiores y, en menor medida, la língula y el segmento lateral del lóbulo medio, con un leve derrame pleural bilateral. Se descartó la presencia de masas pulmonares (Figura 2).

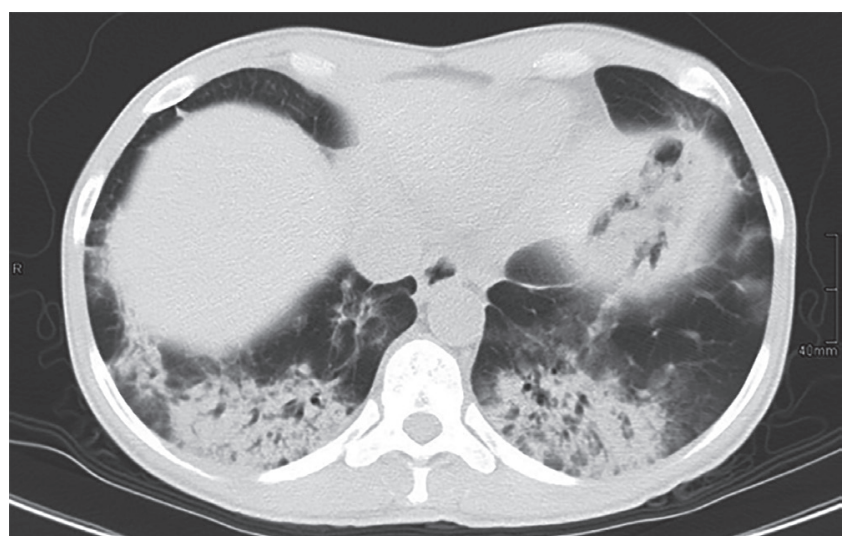

Figura 2. Tomografía de tórax de alta resolución: extensas áreas con aumento de la atenuación pulmonar (franca consolidación) con broncograma aéreo asociado con un patrón de vidrio deslustrado que compromete ambos segmentos basales posteriores de los lóbulos inferiores y, en menor medida, la língula y el segmento lateral del lóbulo medio, con leve derrame pleural bilateral.

Debido al cuadro clínico de la paciente se consideró como diagnóstico una neumonía con germen persistente frente al SEP de causa miscelánea (neumonía organizada), por lo cual se consideró escalar el manejo antibiótico. Se le realizó una fibrobroncoscopia que mostró un proceso inflamatorio agudo del árbol traqueobronquial; se tomó una muestra de LBA y biop- sia. En el análisis del LBA, los datos de celularidad muestran un patrón granulocítico mixto de predominio neutrofílico (neutrófilos: $41 \%$, eosinófilos: $13 \%$ ). En la biopsia transbronquial, los alvéolos muestran escasos histiocitos y eosinófilos en la luz. Ante el diagnóstico no claro se decidió solicitar una biopsia pulmonar por videotoracoscopia, en la cual el análisis histopatológico reportó una pérdida de la arquitectura pulmonar y un leve compromiso intersticial caracterizado por el engrosamiento septal secundario a proliferación de linfocitos e histiocitos. A nivel alveolar se observó una hiperplasia y atipia de neumocitos, y ocupación difusa de la luz por el exudado fibrinoso con abundantes eosinófilos (Figura 3), además de áreas de neumonía de organización caracterizadas por la presencia de pólipos fibroblásticos con eosinófilos confirmados por la coloración de tricrómico (Figura 4). No había presencia de células gigantes, granulomas, membrana hialina, microorganismos, ni neoplasia.

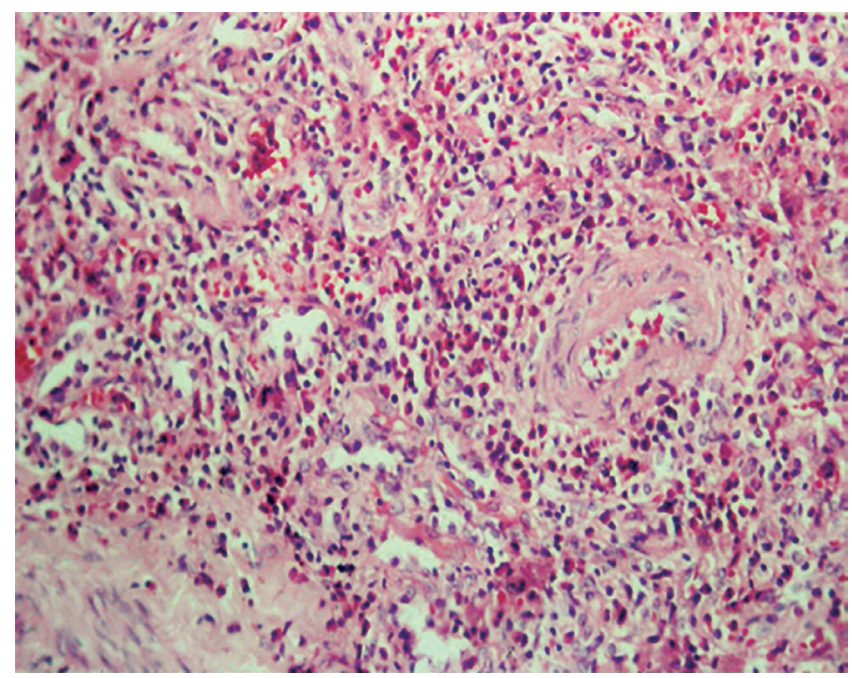

Figura 3. HE 40 X. Ocupación de la luz de los alvéolos por eosinófilos.

Ante los hallazgos del LBA y la biopsia de pulmón se decidió suspender los antibióticos y se inició prednisona $25 \mathrm{mg}$ al día vía oral (VO); a las 72 horas del inicio del tratamiento la paciente mostró una franca mejoría clínica y radiológica (Figura 5). Una semana después de instaurado el tratamiento con esteroides, la eosinofilia periférica desapareció (8230 leucocitos/ $\mathrm{mm}^{3}$, eosinófilos $2 \%$ ), así como en la escanografía de tórax de alta resolución, en la que se observó una 
disminución $>90 \%$ de los infiltrados alveolares de los segmentos posteriores de los lóbulos inferiores con una mejoría notable de las áreas de condensación.

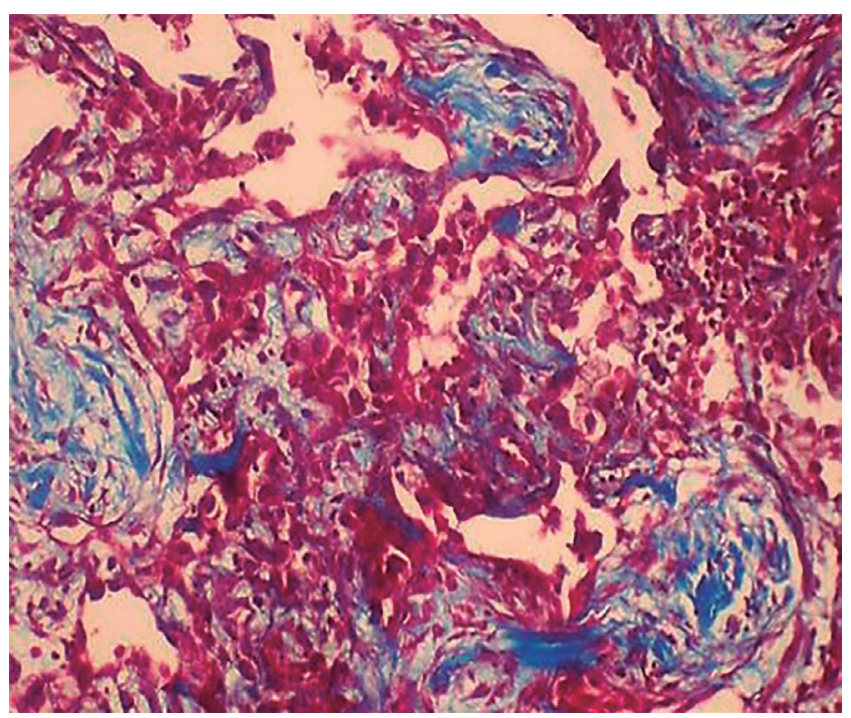

Figura 4. Tricrómico 40 X. Presencia de pólipos fibroblásticos en algunos alvéolos (NO).

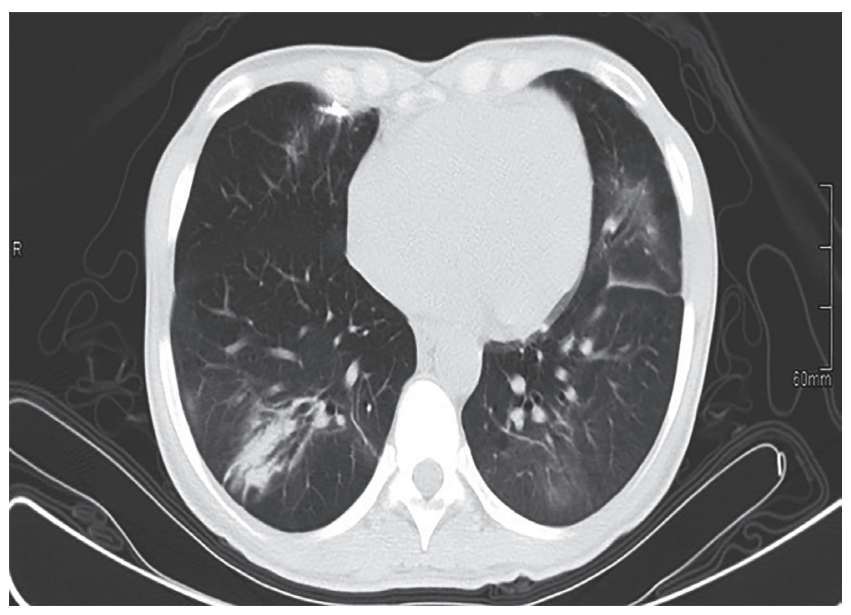

Figura 5. Tomografía de tórax de alta resolución de control, disminución $>90 \%$ de los infiltrados alveolares de los segmentos posteriores de los lóbulos inferiores con mejoría notable de la condensación.

\section{Discusión}

Los SEP pueden clasificarse según la presentación clínico-radiológica y según su etiología (1), entonces puede estarse frente a un cuadro pulmonar agudo o crónico. El abordaje clínico anterior descartó la mayoría de causas secundarias de eosinofilia pulmonar, conside- rando como principales las debidas a parasitosis en el contexto epidemiológico de nuestra área geográfica. El cuadro clínico de presentación de las neumonías eosinofílicas no difiere del de las neumonías típicas adquiridas en la comunidad, ya que el curso clínico y la pobre respuesta al tratamiento antibiótico asociado con una presentación radiológica típica, junto con factores de riesgo dados por sus comorbilidades y la pertenencia a un grupo de edad vulnerable, hace sospechar como primera posibilidad un proceso infeccioso de las vías respiratorias inferiores en el momento de su presentación; de hecho, la mayoría de las neumonías eosinofílicas inicialmente se aborda como procesos bronconeumónicos. El ejercicio médico en este caso es realizar un amplio y acertado diagnóstico diferencial del cuadro clínico, para lo cual es necesario estudiar a los pacientes por aquellas entidades más frecuentes, como parasitosis, infección por micobacterias, enfermedades hematológicas y reumatológicas; cada una de estas con manifestaciones en el pulmón y eosinofilia periférica.

Una NEA se presenta, por una parte, con fiebre, tos, disnea, hipoxemia e infiltrados bilaterales asociados con una rápida recuperación debido al uso de corticosteroides y sin recaídas, según los criterios de Allen y colaboradores en 1989. Por otra parte, Janz y colaboradores (5) describieron como los síntomas más frecuentes en la presentación de NEA la disnea, tos, fiebre mayor de $38{ }^{\circ} \mathrm{C}$ y crepitaciones inspiratorias a la auscultación pulmonar, y la fiebre es un signo primordial en el cuadro clínico de la enfermedad. En cuanto a la neumonía eosinofílica crónica (NEC), se caracteriza por una instauración más insidiosa, con exacerbaciones frecuentes, predominando en el sexo femenino y en edad adulta (6), y es común que el cuadro se acompañe de pérdida de peso; la presentación con insuficiencia respiratoria aguda que amerite ventilación mecánica asistida es rara (7). En la NEA, la eosinofilia en sangre periférica no es lo común, como sí lo es en la NEC (8). La elevación de reactantes de fase aguda es más frecuente en la NEA. El estudio radiológico en la NEA se caracteriza por infiltrados de ocupación alveolar y reticulares bilaterales que no son periféricos y la mayoría presenta derrame pleural en algún momento de la evolución (9); en cambio, en la NEC los infiltrados son periféricos, migratorios y 
bilaterales. En los estudios tomográficos, la NEA se caracteriza por áreas con atenuación en vidrio deslustrado bilaterales, consolidación y engrosamiento de la trama broncovascular con un patrón de infiltrado de distribución periférica en más del $50 \%$ de los casos $(10,11)$ asociado con derrame pleural, patrón que no es típico en la NEC.

En este caso la paciente presentó un cuadro agudo con la presencia de fiebre, tuvo leve insuficiencia respiratoria con hipoxemia y presentaba eosinofilia periférica con elevación de reactantes de fase aguda e infiltrados mixtos, patrón en vidrio esmerilado y derrame pleural bilateral. En este contexto se estaba ante un caso con presentación clínica de NEA con respuesta clínica y radiológica significativa a los corticosteroides. Pasados 7 días, la paciente tenía mejor estado general y logró continuar con sus actividades cotidianas. Se concluye que la paciente se presentó con un cuadro NEA.

\section{Referencias}

1. Campos LE, Pereira LF. Pulmonary eosinophilia. J Bras Pneumol. 2009;35(6):561-73.

2. Cottin V. Eosinophilic Lung Diseases. Clin Chest Med. 2016;37(3):535-56.
3. Contreras A, Rossi C, Schwartz A. Acute eosinophilic pneumonia. Pathology Case Review. 2007;12(3):100-4.

4. Shorr AF, Scoville SL, Cersovsky SB, Shanks GD, Ockenhouse CF, Smoak BL, et al. Acute eosinophilic pneumonia among US Military personnel deployed in or near Iraq. JAMA. 2004;292(24):2997-3005.

5. Janz DR, O’Neal HR Jr, Ely EW. Acute eosinophilic pneumonia: A case report and review of the literature. Crit Care Med. 2009;37(4):1470-4.

6. Alam M, Burki NK. Chronic eosinophilic pneumonia: a review. South Med J. 2007;100(1):49-53.

7. Marchand E, Reynaud-Gaubert M, Lauque D, Durieu J, Tonnel $\mathrm{AB}$, Cordier JF. Idiopathic chronic eosinophilic pneumonia. A clinical and follow-up study of 62 cases. The Groupe d'Etudes et de Recherche sur les Maladies "Orphelines" Pulmonaires (GERM"O”P). Medicine (Baltimore). 1998;77(5):299-312.

8. Hayakawa H, Sato A, Toyoshima M, Imokawa S, Taniguchi M. A clinical study of idiopathic eosinophilic pneumonia. Chest. 1994;105(5):1462-6.

9. King MA, Pope-Harman AL, Allen JN, Christoforidis GA, Christoforidis AJ. Acute eosinophilic pneumonia: radiologic and clinical features. Radiology. 1997;203(3):715-9.

10. Daimon T, Johkoh T, Sumikawa H, Honda O, Fujimoto K, Koga T, et al. Acute eosinophilic pneumonia: Thin-section CT findings in 29 patients. Eur J Radiol. 2008;65(3):462-7.

11. Jeong YJ, Kim KI, Seo IJ, Lee CH, Lee KN, Kim KN, et al. Eosinophilic lung diseases: a clinical, radiologic, and pathologic overview. Radiographics. 2007;27(3):617-37. 